ص ص [118-105]

$$
\begin{aligned}
& \text { دالة عضوية مقترحة لعينة من التباتات الطبية باستخدام } \\
& \text { نظرية المجموعات المضببة مئة }
\end{aligned}
$$

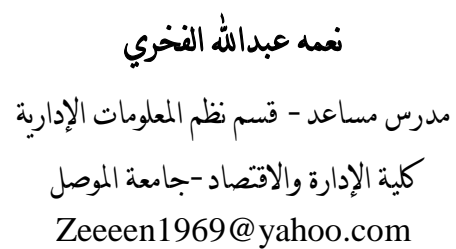

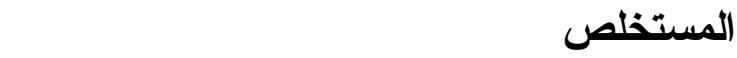

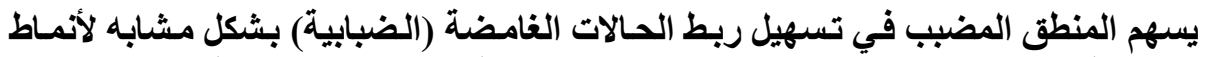

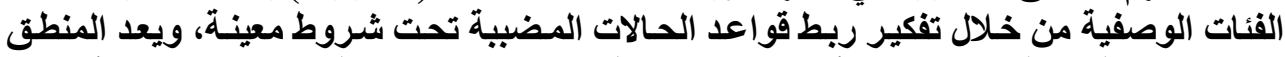

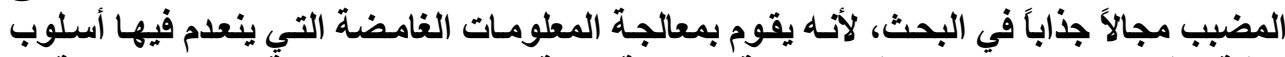

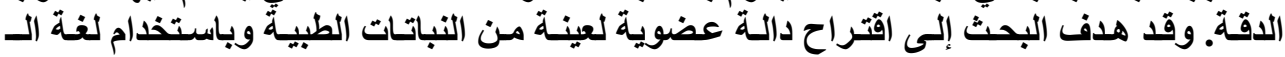
Mathlab

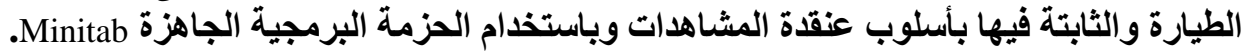

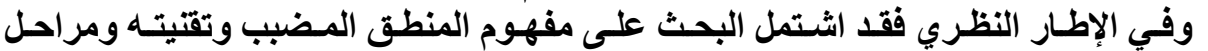

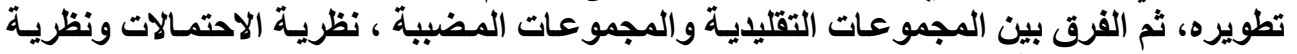
المجموعات المضبية. وقد خلص البحثث إلى أنـه كلمـا كانت نسبة الزيوت الطيارة عاليـة في النبات فإنها يعد من النباتات العطرية.

\title{
A Suggested Membership Function to a Sample of Medicinal Plants By Using Fuzzy Sets
}

\author{
Neima A. Al-Fackry \\ Assistant Lecturer \\ Department of Management Information Systems \\ University of Mosul
}

\begin{abstract}
Fuzzy logic that facilitates linking the ambiguous situations (fuzzy) is similar to patterns of descriptive categories of thinking through the linkage of cases under certain conditions. Fuzzy logic is attractive subject in search of the address information that there are ambiguous style precisions. The goal of the search function to propose a membership of a sample of medical plants and using the language of MATHLAB after the data were a
\end{abstract}


cluster of plants with similar characteristics depending on the percentage of volatile oil and fixed by a cluster observations using software package MINITAB. In theoretical part, the research included a definition of the fuzzy logic and its technique, phases of logic, differences between crisp sets and fuzzy sets, probability theory and fuzzy logic theory.

المقدمة

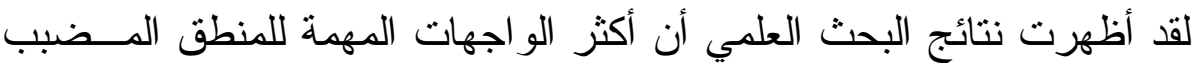

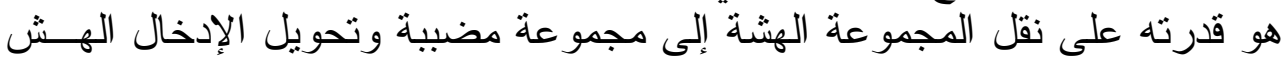

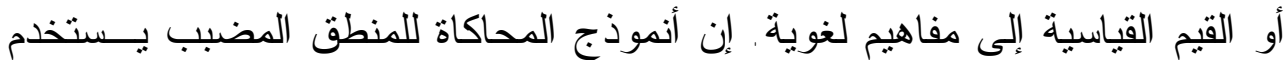

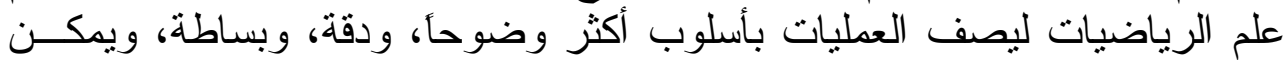

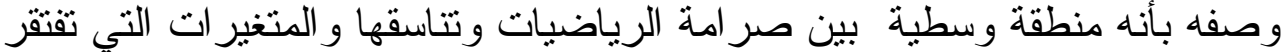

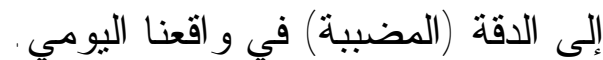

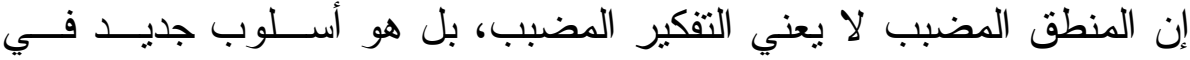
التفكير لمعالجة حالات الغموض واللا دقة الموجودة في حياتتا اليومية.

المنطق الضبابي الغامض الذي يسمى أيضاً المنطق المبهم المائع، أو المنطق

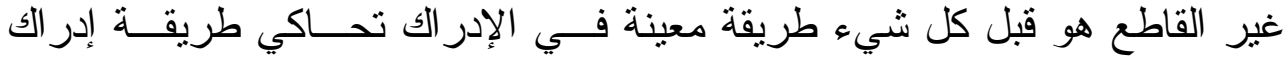

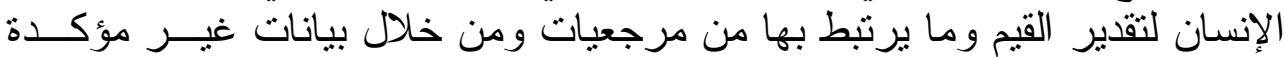

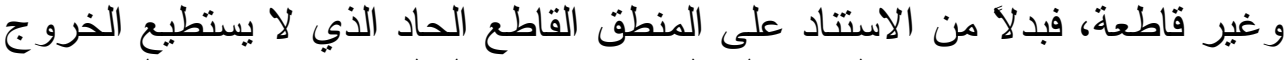

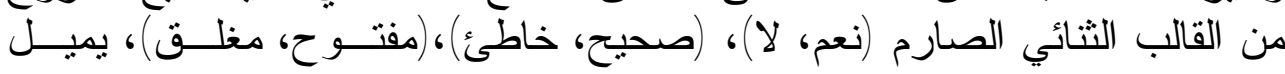

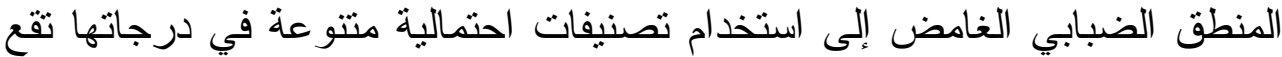

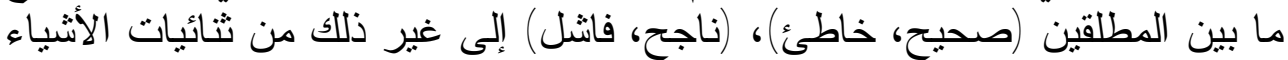

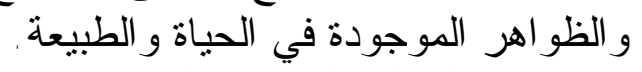
إذن المنطق الضبابي الغامض هو شكل أو أو إطار لإدر الك وتفكير جديد، تفكير

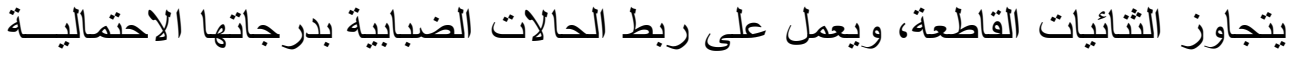
بشكل مشابه لأنماط الفئات الوصفية المتعددة (التكريتي، 2007، 193).

\section{2. مراحل تطوير المنطق المضبب}

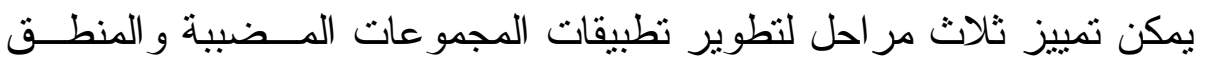

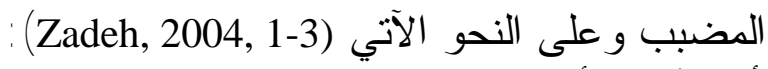

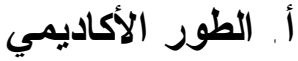

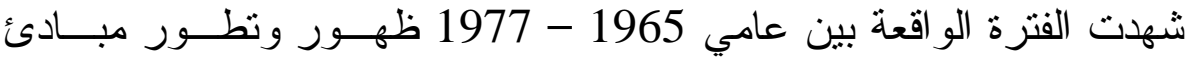
نظرية الهجموعات المضيبة وبعض لالنطبيقات النظرية وكانت حصيلة هذا النطور 
عدداَ قليلا من الإصدار ات، المنشور ات ذات الطبيعة النظرية التي أصدر ها عــدد

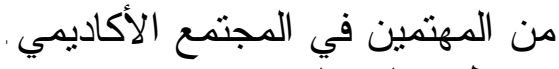
ب. طور التحول

لم تتغير الفترة الو اقعة بين عامي 1978 - 1988 بتقدم نظرية المجمو عات المضببة فقط ولكن بظهور بعض التطبيقات العملية الناجحة للنظريــة المــضبية،

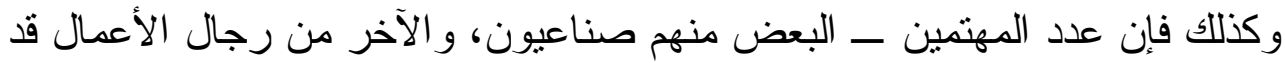

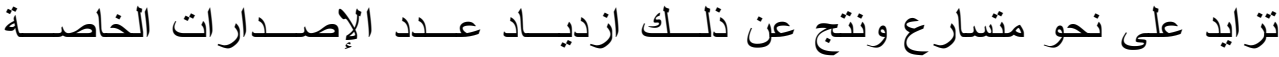
بالموضوع، البعض منها ناقش التطبيقات العملية في مجال المنطق المضبب، التب، كذلك فقد كرست بعض الإصدار ات المتخصصة من أجل التعريف بــالمنطق المــضب في وتطبيقاته .

ت. طور الآفجار المضبب

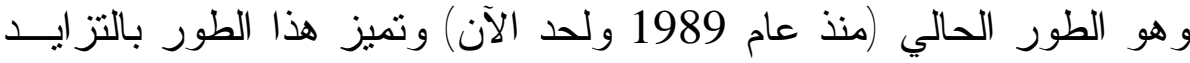

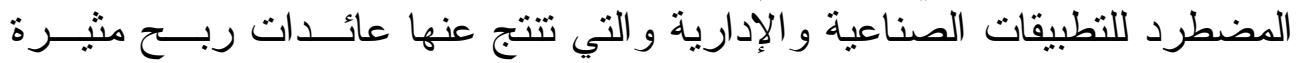

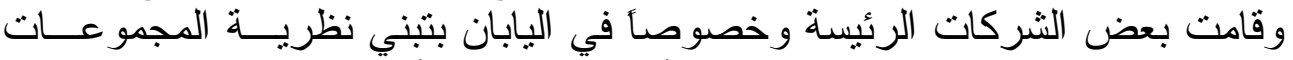

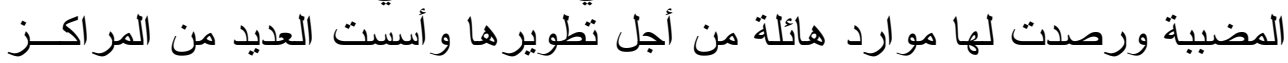

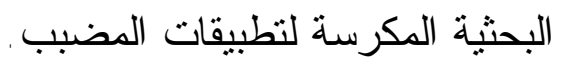

\section{3. تقنية المنطق المضبب}

المنطق المضبب هو في حقيقة الأمر منطق حاسوبي يقوم على الاحتماليــة،

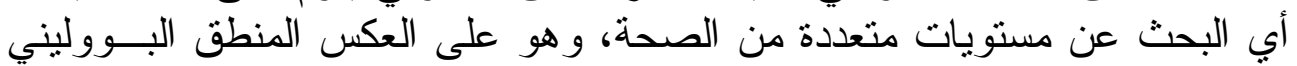
الذي تعتمد عليه النظم المحوسبة الحديثة التي تعالج القضايا الصحيحة و الخاطئـة بالرقمين (0،1،)، وقد تطور المنطق المضبب في جامعة كاليفورنيا الأمريكية لتمكين

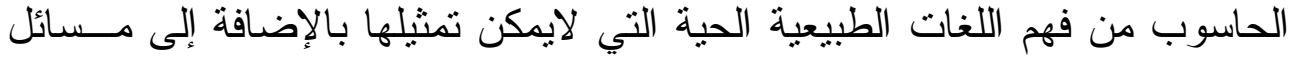

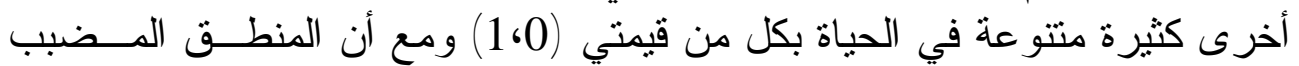

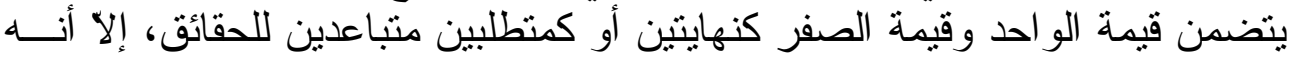

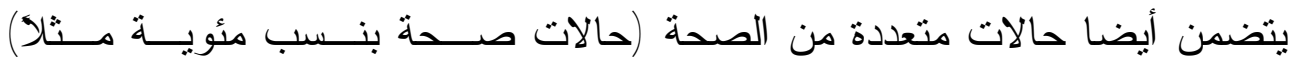

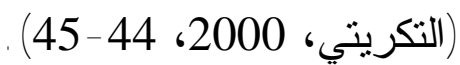
ويعد المنطق المضبب الطريقة الأنسب في تطبيق قو اعد الضبط التي لايمكن

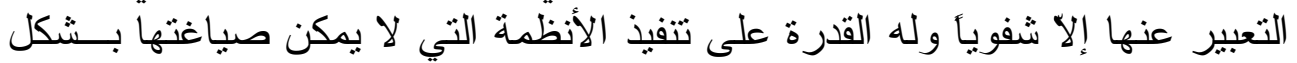

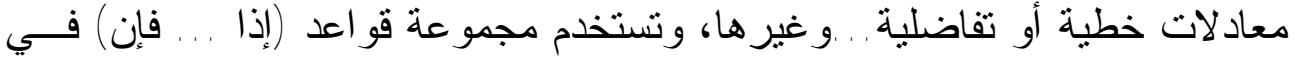

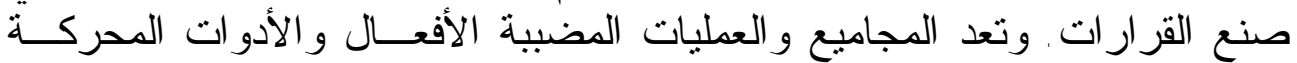

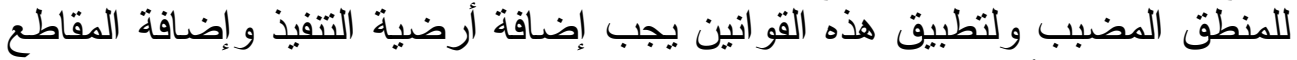
اللازمة، ويجب أن تكون الجملة متكاملة (Hawick, 2004, 526). 


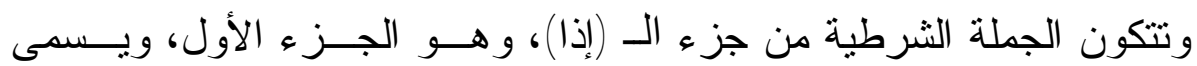

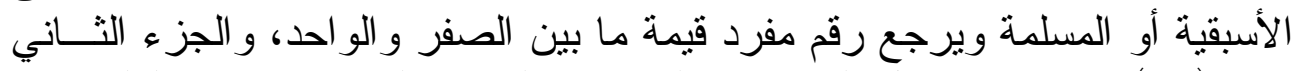

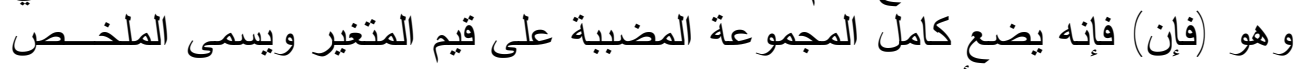

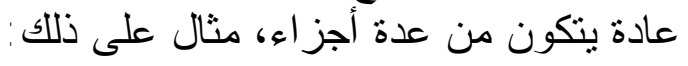

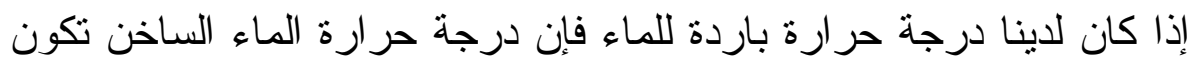

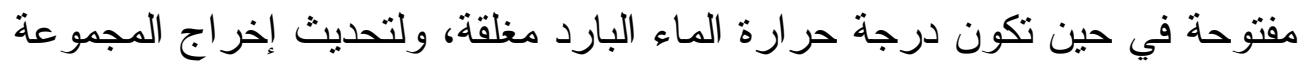

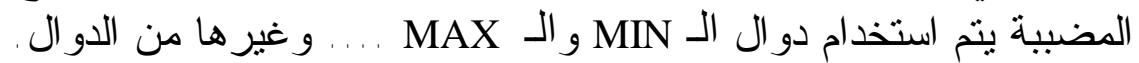

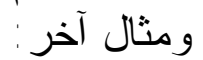
1. إذا كان الخزان ممتلئًا أوقف عملية المله.

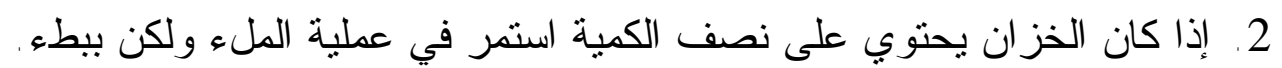

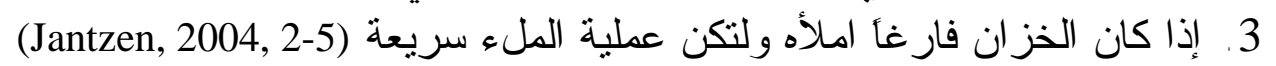

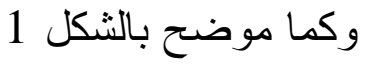
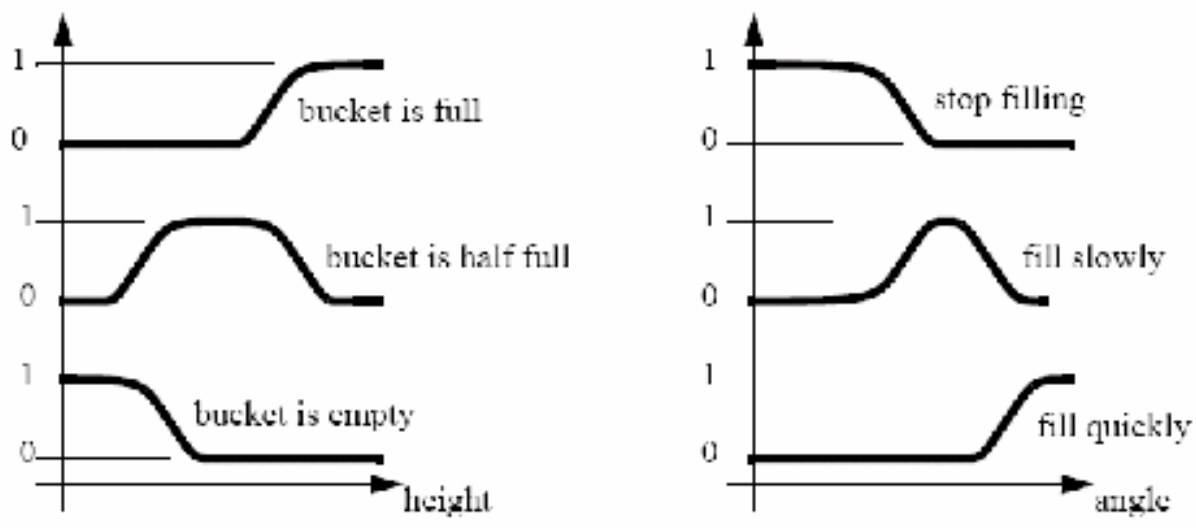

\section{(الثكل وبران 1}

مر احل ملء الخزان وببرع متفاوتة

إن نظم المنطق الضبابي المحوسب على عكس النماذج الاحتمالية الإحصائية

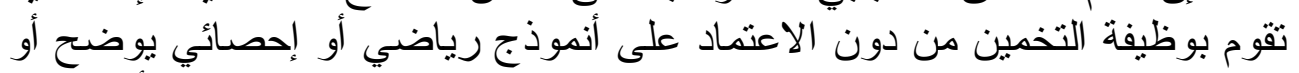

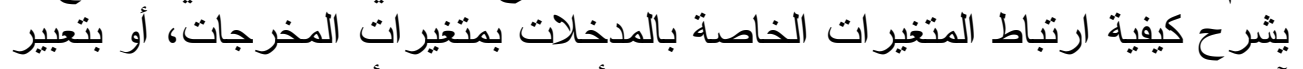

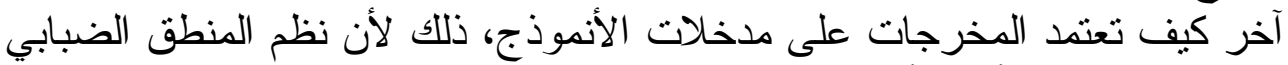

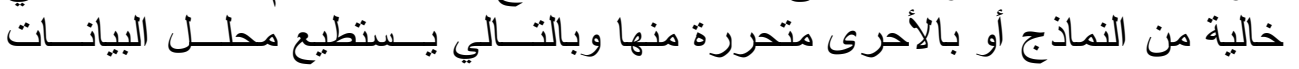

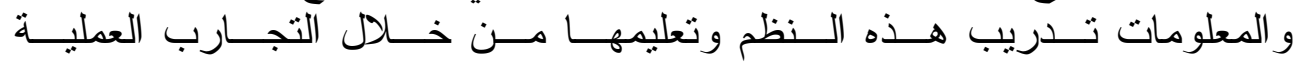

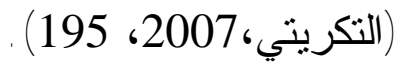


4. المجموعات التقليدية والمجموعات المضببة

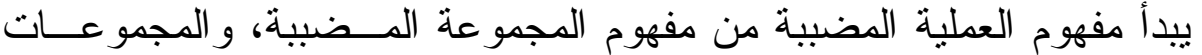

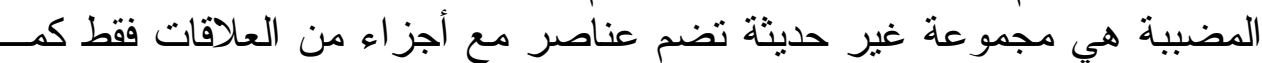

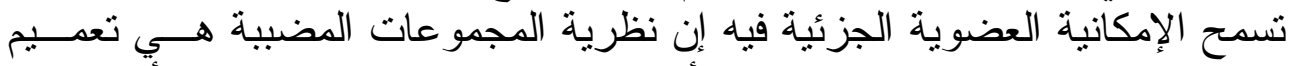

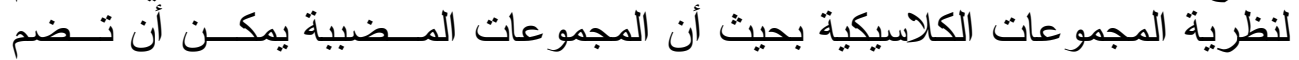
المجموعات الكلاسيكية كحالة خاصة و المجموعات الكلاسيكية تعرف المجموعــة

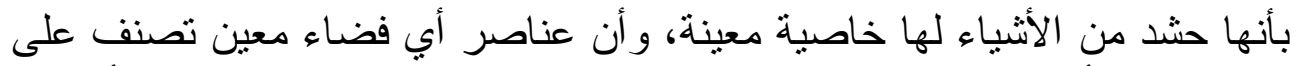

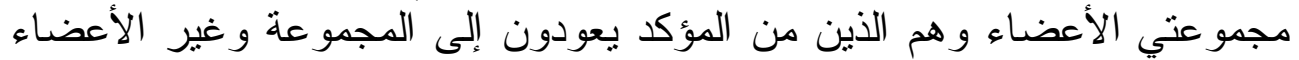

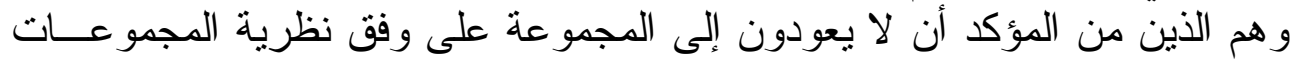

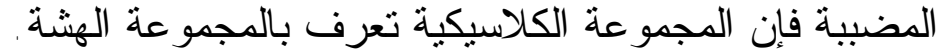

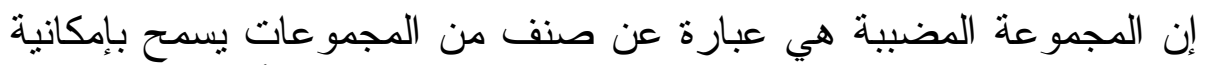

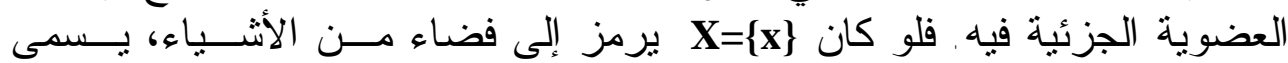

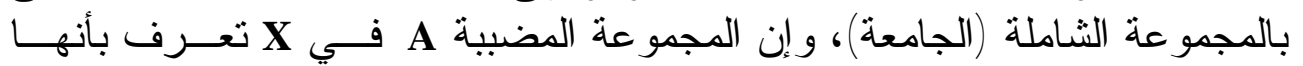

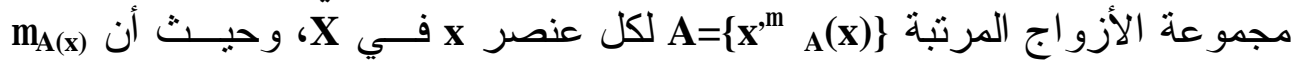

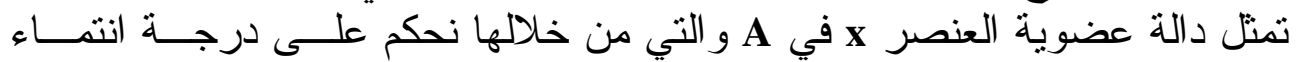

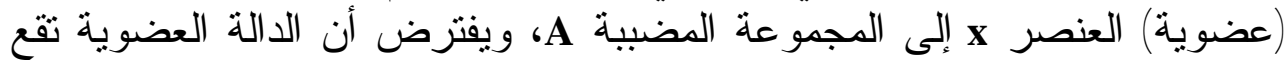
في الفترة [0، 1]، و أن 0 يرمز لعدم العضوية في حين أن 1 يرمز للعضوية الكاملة (الخياط، 2004، 4 - 4 -5) .

\section{5. نظرية المجموعة المضببة ونظرية الاحتمالات}

قبل وضع نظرية المجموعات المضبية كانت نظرية الاحتمالاته واتهات هي النظرية

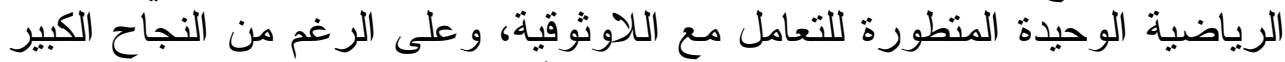

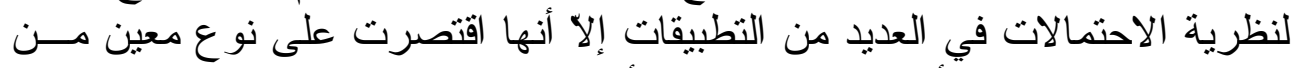

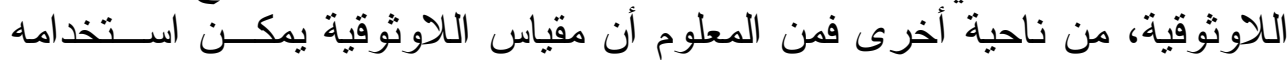

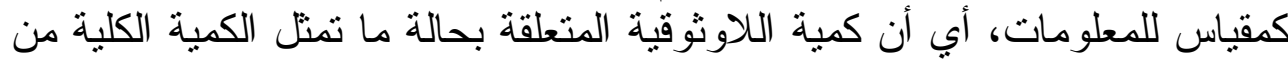

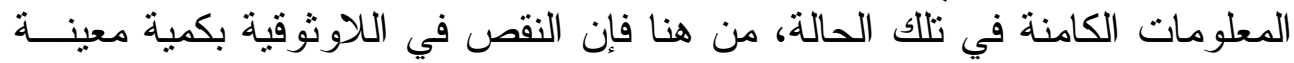

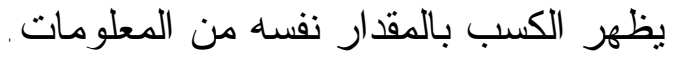

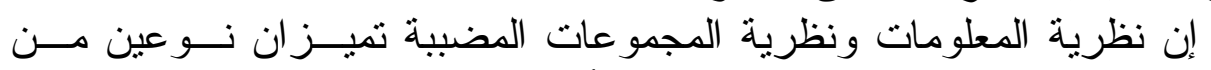

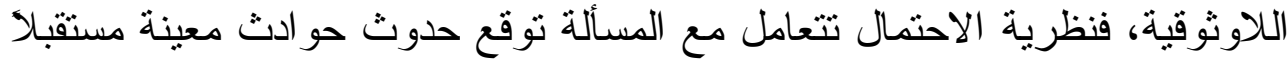

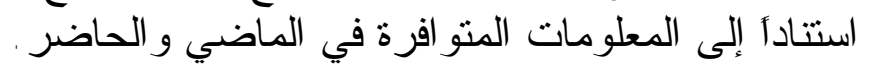
و هناك شعور بوجود بعض التشابه بين مفهومي التضبيب واتئ والاحتمالية، حيث

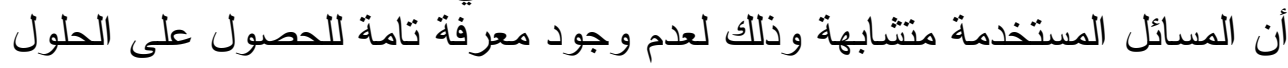

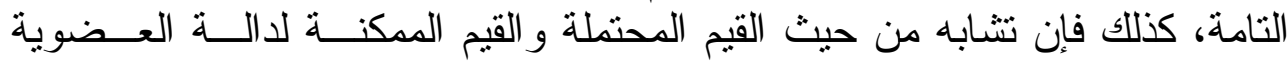

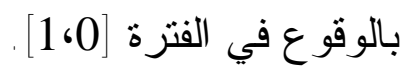




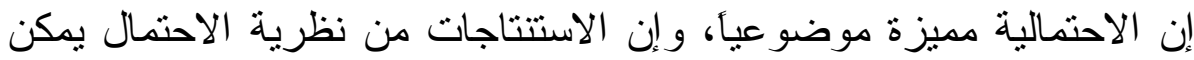

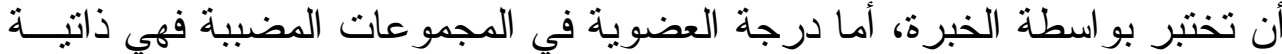

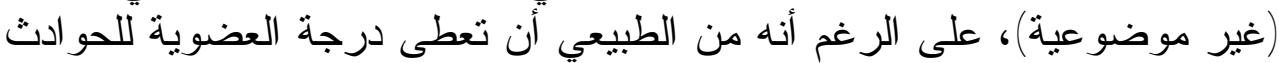

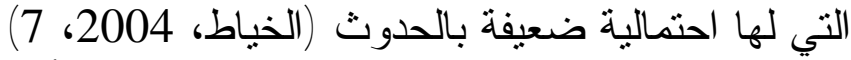

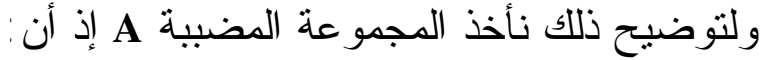

$$
A=\left\{x ; y^{\prime \prime}|x-y| \approx 1\right\}
$$

$$
\mu_{A}(x, y)=e^{-|x-y|}
$$

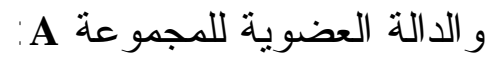

وبحسب نظرية المجمو عات المضيبة يمكن تفسير قيم المجموعة A A من خلال

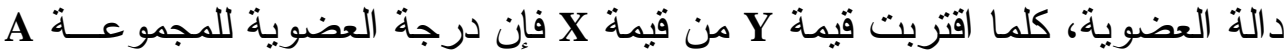

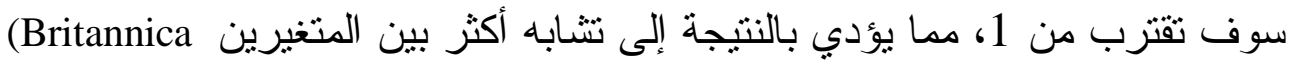
concisa Encyclopedia: probability theory, 2005)

يتضمن الجانب العملي مرحلتين: الأولى، عنقدة البيانات إلى مجاميع متماتلة الزئة

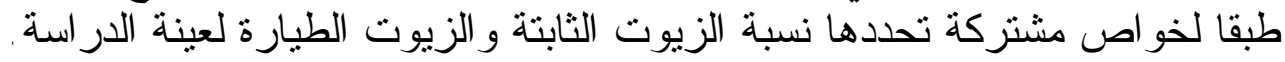

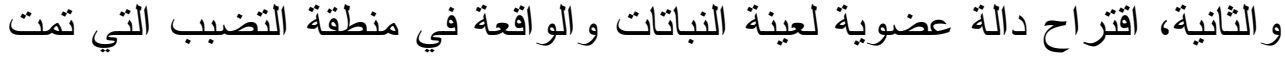
عنقدتها باستخدام نظرية المجمو عات المضبية.

\section{أولاً - استخدام التحليل العنقودي للحصول على المجاميع المتثابهة}

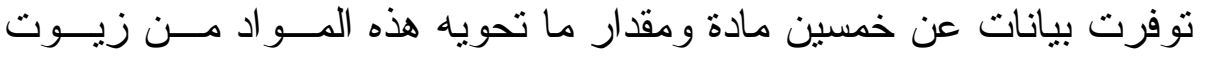

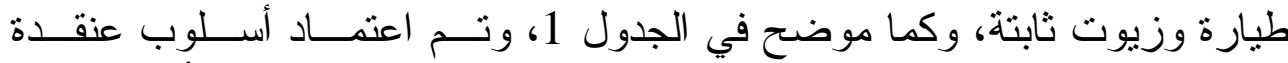

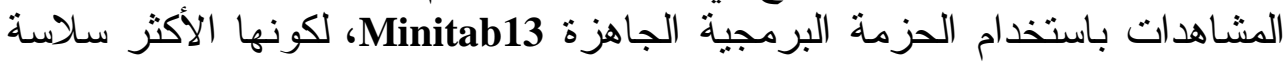
ودبساطة بين البرامجيات الجاهزة و التي تمكن من الحصول على نلى نتائج ميسرة الفهر

\begin{tabular}{|c|c|c|c|}
\hline \multicolumn{4}{|c|}{ البيانات عينة البحث 1 الجدول } \\
\hline الاستعمال & المو اد الكيميائية ونسبتها & المادة & $ت$ \\
\hline منبه قابض ويستخرج الكافيين من & زيت طيار 1 -5 كافيين & الثناي & 1 \\
\hline الككونـات الكيميائية & $\begin{array}{c}0.5 \\
\text { مو اديتوية طيار }\end{array}$ & 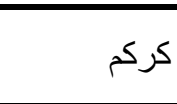 & 2 \\
\hline الغذاء، مدر لحليب الأمهات & زيت طبار 1.05 زيت 6.0 & الحلبة & 3 \\
\hline الدباغة و إنتاج الحبر & 50 -70 من المو اد القابضة & العفص & 4 \\
\hline
\end{tabular}

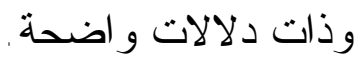




\begin{tabular}{|c|c|c|c|}
\hline الاستعمال & المو اد الكيميائية ونسبتها & المادة & $ت$ \\
\hline الأصباغ و الالتهابات الجلدية & زيت طبار 0.01\% & الحناء & 5 \\
\hline مسهل وفاتح للشهية & 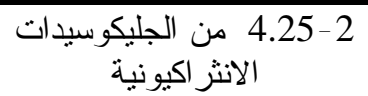 & | ل راوند & 6 \\
\hline منبه عطري ومضاد للبرد & زيت ثابت طيار -13 8 -13 & | ز عفر ان & 7 \\
\hline مسهل قوي & & سنامكي اسكندر اني & 8 \\
\hline طارد للبغلم، يغلف قرحة المعدة & & عرقسوس & 9 \\
\hline محسن لطعم المأكو لات & زيت طيار 2-1و 4 & فانيليا & 10 \\
\hline مشروب منشط للجهاز العصبي & زرونين ثابت 2 - 2 -12 & ] بن & 11 \\
\hline منبه خفيف، في صناعة الثوكو لا & 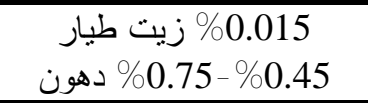 & 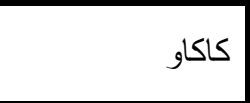 & 12 \\
\hline علاج الملاريا، مقوي للمعدة & M 0.01 زيت طيار & خشب الكينا & 13 \\
\hline علاج للإسهال، طارد للايدان & & قتشر رمان & 14 \\
\hline مقوي، فاتح للشهية & & فلفل اسود & 15 \\
\hline طارد للغاز ات، منبه عطري & زيت طبار 1.4 -2 & ق ق قرفة & 16 \\
\hline مسكن لآلام الأسنان & زيت طيار 1.4 -21 & قرنفل & 17 \\
\hline مهذئ للجهاز العصبي & 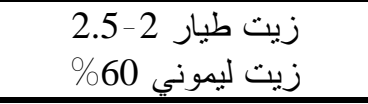 & 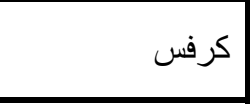 & 18 \\
\hline طارد للغاز ات، مسكن للآلام، & زيت طيار 0.5 -1-1 & كزبرة & 19 \\
\hline طارد للغاز ات،مسكن للآلامكتو ابل & 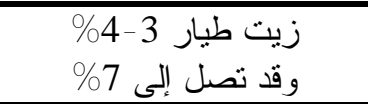 & كمون & 20 \\
\hline تو ابل، صناعة المنثول و العطور & 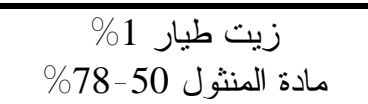 & نعناع فلفلي & 21 \\
\hline صناعة العطور، تحسبين طعـم & 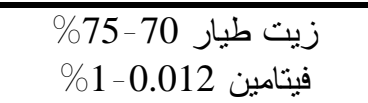 & | - الورد & 22 \\
\hline صناعة العطور غالية الثنن & زيت طيار 0.15\% & ياسمين & 23 \\
\hline طارد للغاز ات، مسكن للألم & زيت طبار 2 -3\% & الينسون & 24 \\
\hline طارد للغاز ات، منشط عام & زيت ثيت 5 زيت -25 -50\% & | جوزة الطيب & 25 \\
\hline علاج للربو، طارد للبلغم، تو ابل & زيت طيار 1,5\% ز33\% & حبة البركة & 26 \\
\hline طارد للغاز ات، علاج للرومــاتزم، & زيت طيار 0.4 -0.5\% & 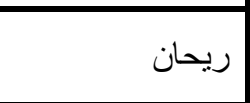 & 27 \\
\hline تو ابل، طارد للغاز ات & 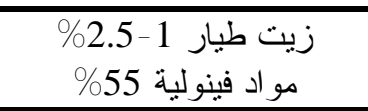 & 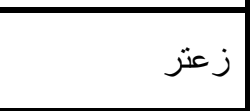 & 28 \\
\hline مسكن، طارد للغاز ات & زيت طبار 3 -4\%\% & تشبت & 29 \\
\hline
\end{tabular}




\begin{tabular}{|c|c|c|c|}
\hline الاستعمال & المو اد الكيميائية ونسبتها & المادة & $ت$ \\
\hline & مادة الكارفون 53 -63\% & & \\
\hline مستحضر ات التجميل & 0.01 \%زيت طيار & زنبق & 30 \\
\hline للغاز ات مشروب مغذي للأطفــال، طــــارد & زيت ثابت 8 -10 -10\% 3 زيار & 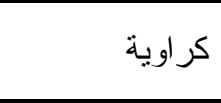 & 31 \\
\hline مسكن للآلام ومنوم & زيت طيار 0.01\% زيت طيار & القنب & 32 \\
\hline مطهر ، صنابة الصـابون و الحنجــــة & زيت طيار 4 -5\% 80\% & الكافور & 33 \\
\hline مسكن، طارد للغاز ات & زيت طيار 2 -6\%\% & 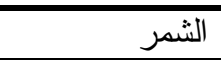 & 34 \\
\hline صلتجميل العطـــور ومستـــــرات & زيت طيار 0.2 -0.3\% & الغتر & 35 \\
\hline صنجاعة العطـــور ومستـــضرات & 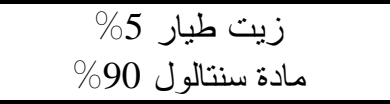 & الصندل الأبيض & 36 \\
\hline 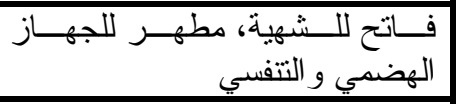 & زيت طيار 1\% & البابونج الألماني & 37 \\
\hline طارد للايدان & 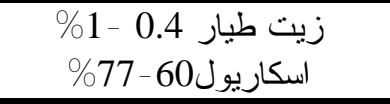 & 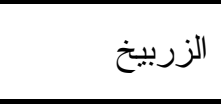 & 38 \\
\hline منوم خفيف ومسكن & زيت طيار 0.3 -1 \% & حشيشة الدينار & 39 \\
\hline يساعد في تسهيل الهضم ومدرر & مو زيت طيار 1.2 مورية 33\% & العرعر & 40 \\
\hline طارد للغاز ات، صناعة العطور & زيت طيار 1\% & حصLالبان & 41 \\
\hline طار للغاز ات، تو ابل & زيت طيار 0.4 \% & بردقوش & 42 \\
\hline طارد للغاز ات، مطهر بولي & & حلفابر & 43 \\
\hline طارد للايدان، صناعة العطور & زيت طبار 0.25 -0.45\% & حشيشة الليمون & 44 \\
\hline طارد للبلغم، منشط للجهاز التتفسي & 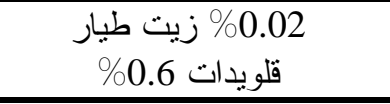 & لولبيا & 45 \\
\hline علاج للروماتزم، فاتح للثهية & زيت طيار ز27 ز27\% & خردل اسود & 46 \\
\hline مقيئ، علاج للروماتزم & زيت ثنابت 27.51 208\% زيت & خردل ابيض & 47 \\
\hline علاج السعال ومقيئ & زيت طبار 1.2\% & عرف الذهب & 48 \\
\hline مقوي & زيت طيار 0.3\% & شيبة & 49 \\
\hline في المأكو لات & زيت طيار 0.3\% & الطرخون & 50 \\
\hline
\end{tabular}

المصدر: حسين، 1981 ، 1916.

ومن أجل تكوين صورة في الذهن وكخطوة أولية لتخمين عدد العناقيد الممكن تكوينها من المشاهدات قيد الدر اسة، تم إجر اء الايعاز ات الخاصة بعنقة التهدة المشاهدات دون تحديد عدد العناقيد المفترضة، وتم المن الحصول على النتائج الموضحة في الملحق 


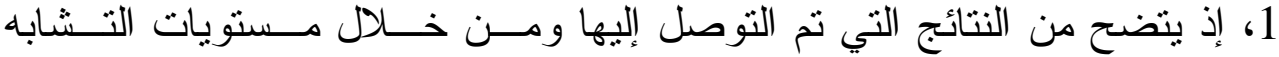
و الاختلاف أنه يمكن عنقدة المشاهدات في أربعة عناقيد و الثكل 2 يوضتح ذلك .

Similarity

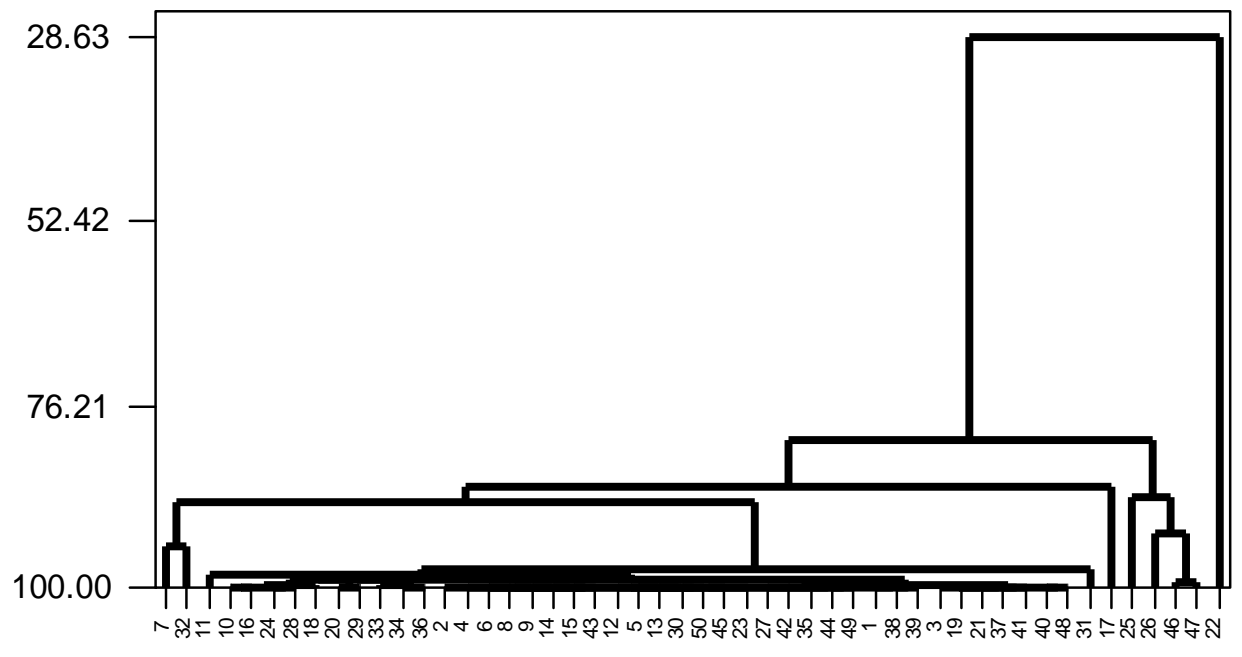

Observations

\section{الشكل 2}

العنقدة من دون تحديا عدد العناقيد

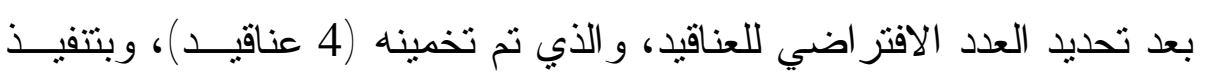

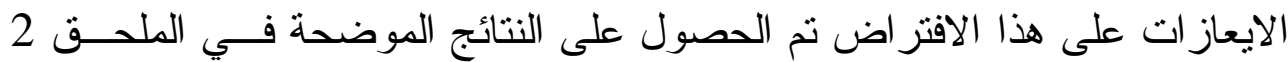

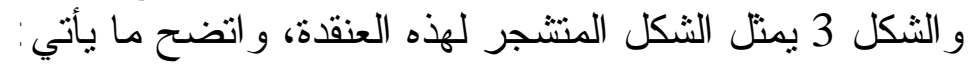

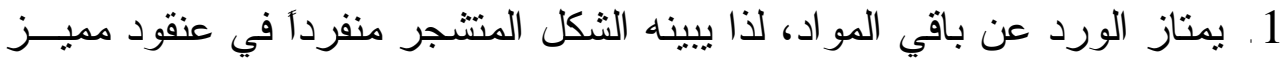

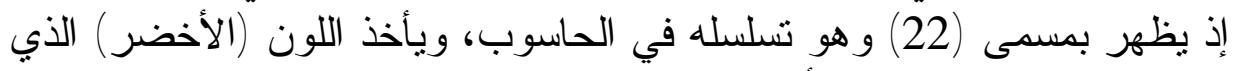

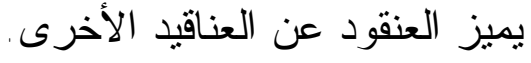

2. يمتاز أيضاً القرنفل بخصائص فريدة تميزه عن باقي المو اد الأخرى، إذ بظهر

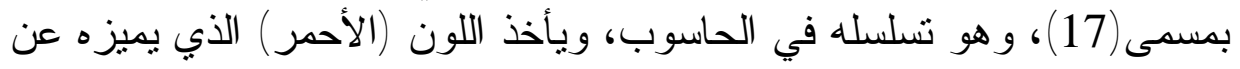
باقي العناقيد .

3. يتضح من الملحق 2 أن كلا من (جوزة الطيب وحبة البركة و الخردل الأبيض

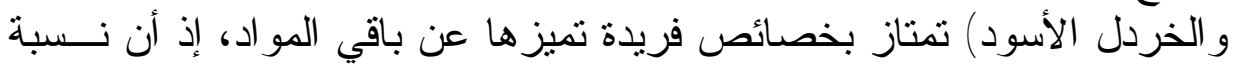

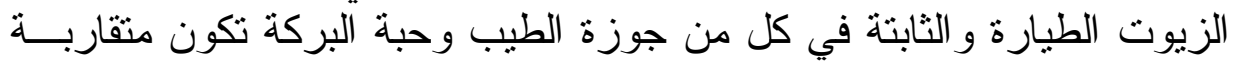

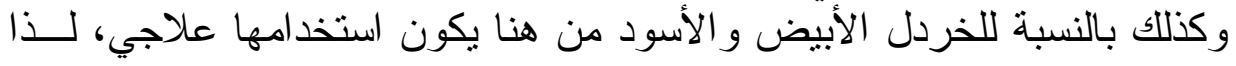


نجدها متعنقدة في عنقود و احد يعرضه الثكل المتـشجر بــاللون (البنفـسجي)

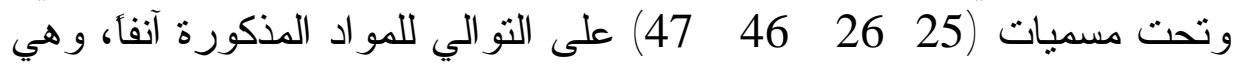

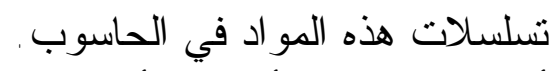

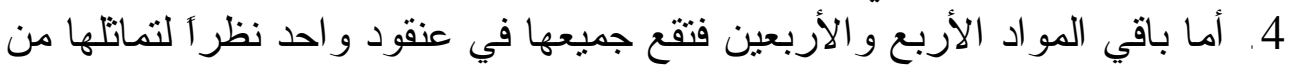

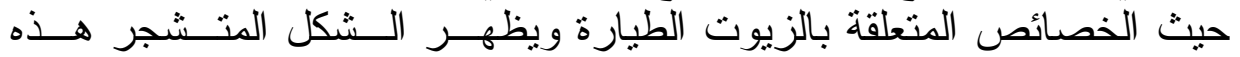

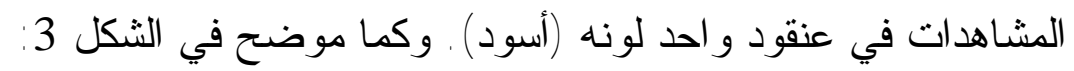

Similarity

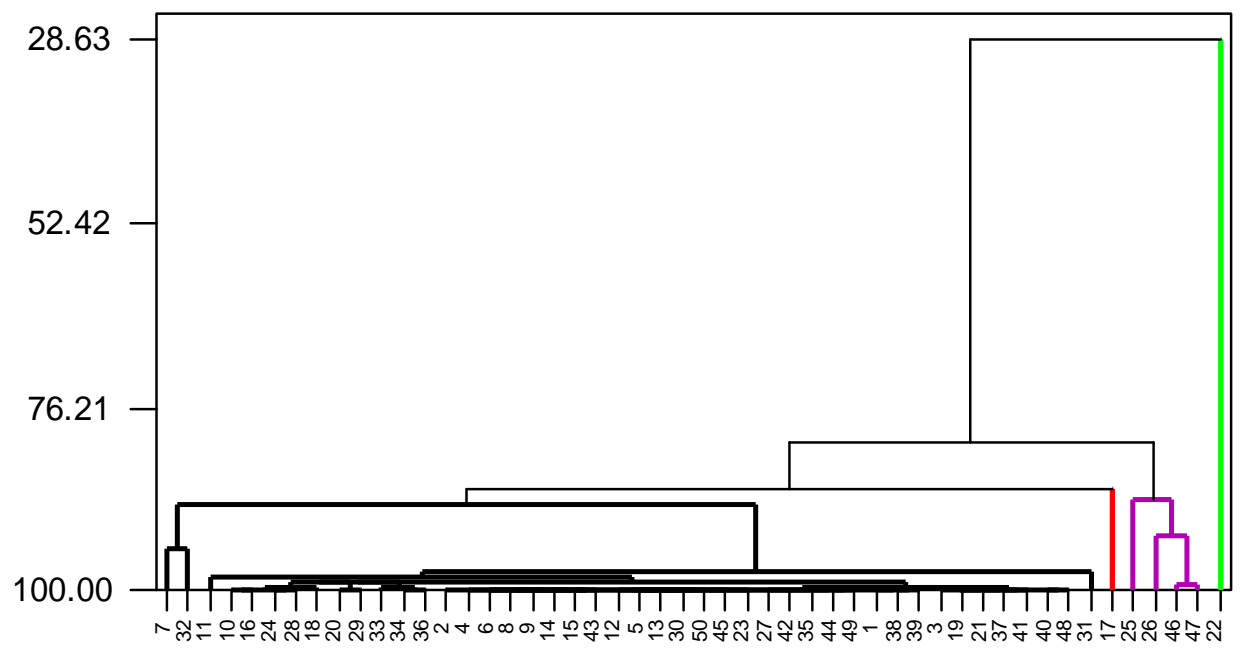

Observations

\section{الثكل 3}

\section{العنقدة بعد تحديا عدد العناقيا بأربعة}

\section{ثانياً - تطبيق دالة عضوية مقترحة}

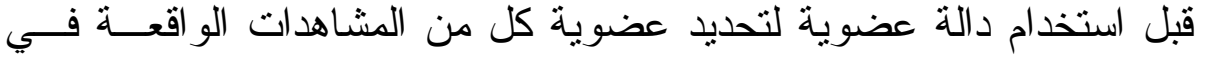

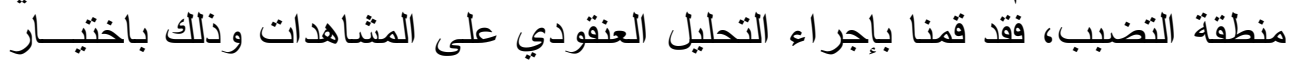

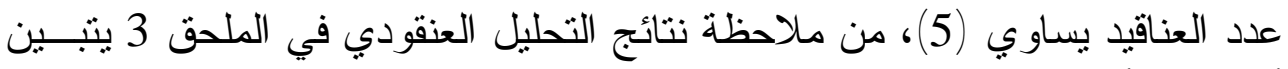

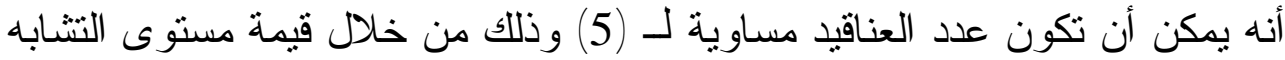

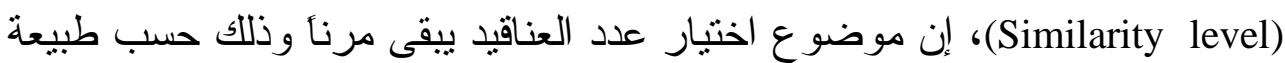

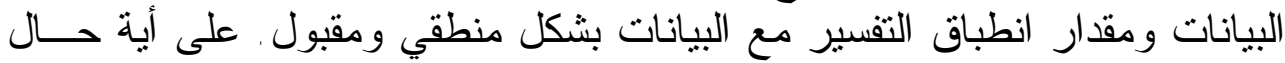

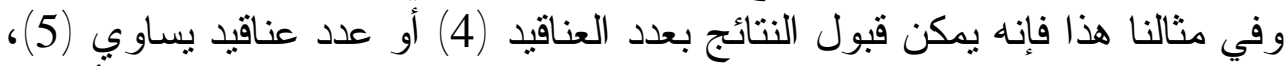
وقد وقع اختيارنا على الحالة الثانية وذللك لكون المخطط الثبكي (المتعنقد) أوضح 
من الحالة السابقة كما يبين ذلك الثكل 4، عليه سيتم في هذه الخطوة حصر عـدـد

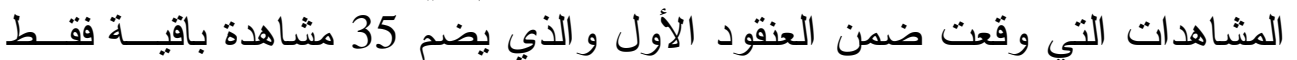

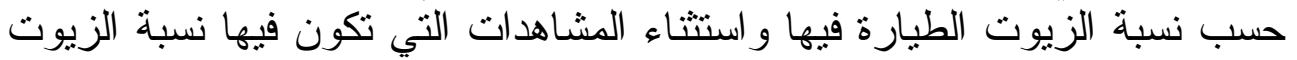

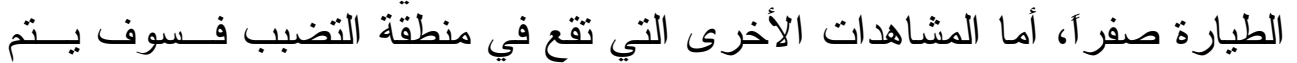

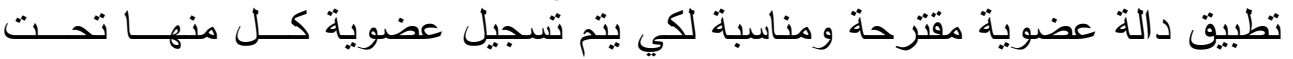
المجموعة الضبابية، إن الدالة العضوية المقترحة مبية دينة في العلاقة الآتية: $\mu_{\mathrm{A}}(\mathrm{y})\left\{\begin{array}{c}0 ; \mathrm{y}<0.4 \\ =\frac{1.1 y-0.4}{y} ; 0.4 \leq y \leq 3 \\ 1 ; \mathrm{y}>3\end{array}\right.$

إذ تمثل (y) البيانات الو اقعة في منطقة التضبب وتم إعطــاء القيمــة (1) إذا كانت قيمة (y) أكبر من 3 أما البيانات التي تكون نسبة الزيوت فيهة فئا أقل مــن 0.4

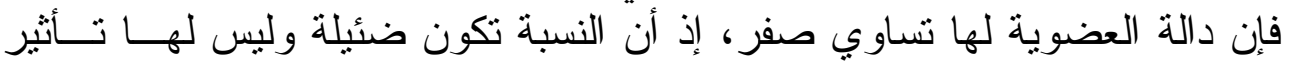
ملحق 4.

Similarity

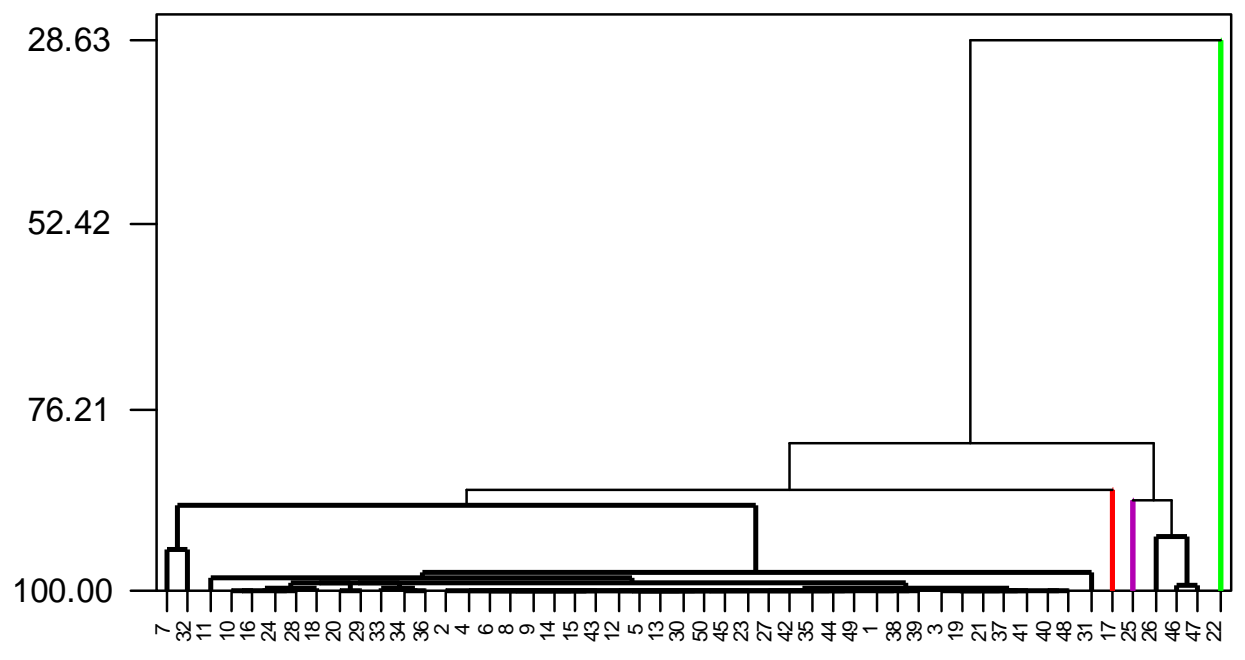

Observations

\section{الشكل}




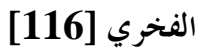

العنقدة بعد تحديد عدد العناقيد بـ 5

(الجدول 2

دالة العضوية للنباتات (المشاهدات) الواقعة في منطقة التضبب

\begin{tabular}{|c|c|c|}
\hline قيمة الدالة & اسم المادة & التسلسل \\
\hline 1 & كر اوية & 1 \\
\hline$\overline{1}$ & الصندل الأبيض & 2 \\
\hline 1 & الشمر & 3 \\
\hline 1 & الكافور & 4 \\
\hline 1 & الثبت & 5 \\
\hline 1 & الكمون & $\overline{6}$ \\
\hline 0.9822 & كرفس & 7 \\
\hline 0.9518 & فانيليا & 8 \\
\hline 0.9518 & قرفةة & 9 \\
\hline 0.9400 & ينسون & $\overline{10}$ \\
\hline 0.9400 & زعتر ل زعت & 11 \\
\hline 0.7666 & حصاالبان & 12 \\
\hline 0.7666 & عرف الذهب & 13 \\
\hline 0.7190 & الحلبة & $\overline{14}$ \\
\hline 0.7000 & كزبرة & 15 \\
\hline 0.7000 & نعناع فلفلي & 16 \\
\hline 0.7000 & البابونج الالماني & 17 \\
\hline 0.7000 & العر عر & $\overline{18}$ \\
\hline 0.5666 & الثاي & $\overline{19}$ \\
\hline 0.5285 & الزربيخ & 20 \\
\hline 0.4846 & حشيشة الدينار & 21 \\
\hline 0.3 & الريحان & 22 \\
\hline$\overline{0.1}$ & البردقوش & 23 \\
\hline 0 & حشيشة الليمون & 24 \\
\hline 0 & الثيبية & 25 \\
\hline$\overline{0}$ & باسمين & 26 \\
\hline$\overline{0}$ & لوليبا & 27 \\
\hline$\overline{0}$ & الكاكاو & 28 \\
\hline$\overline{0}$ & الحناء & 29 \\
\hline
\end{tabular}




\begin{tabular}{|c|c|c|}
\hline 0 & خشب الكينا & 30 \\
\hline 0 & الزنبق & 31 \\
\hline 0 & الطرخون & 32 \\
\hline 0 & الغتز & 33 \\
\hline 0 & القنب & 34 \\
\hline 0 & الكركم & 35 \\
\hline
\end{tabular}

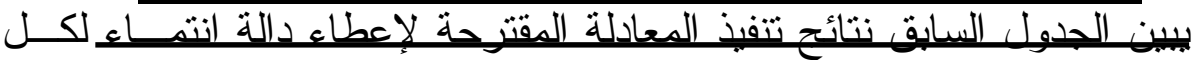

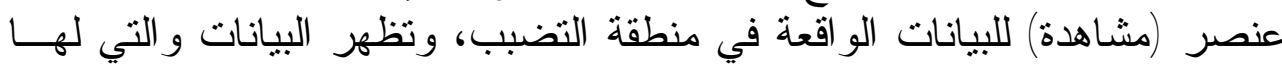

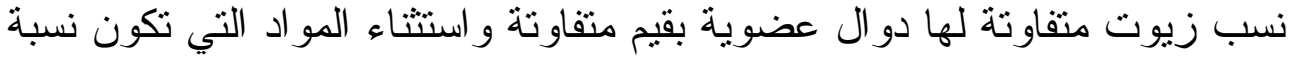

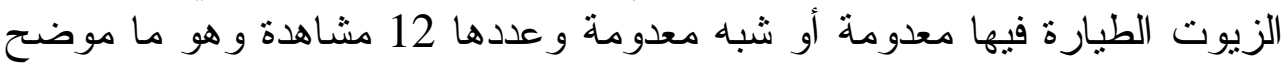

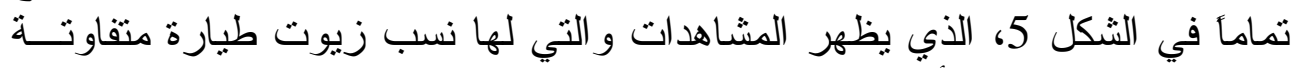

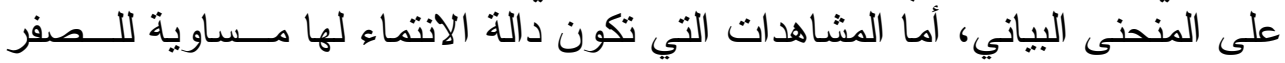

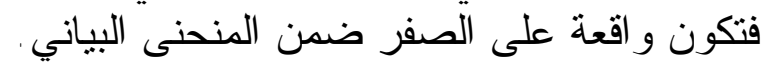

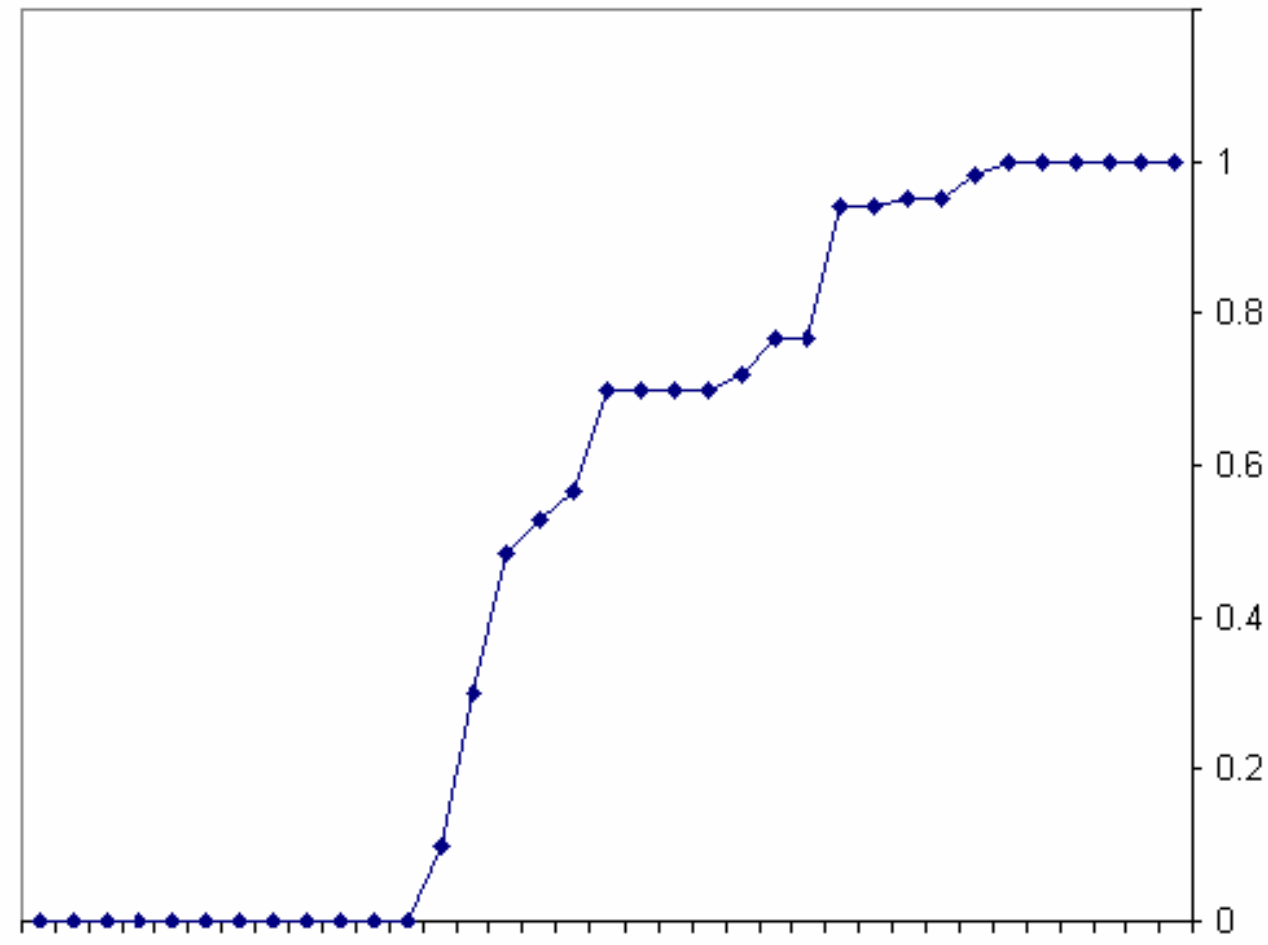

5 الشكل

درجة الاتماء لبيانات المشاهدات الواقعة في منطقة التضبب 
1 ـ يمكن ربط البيانات من حيث خصائصها و استخدام التحليل العنقودي في تصنيف البيانات من حيث مستوى التشابه لتكوين عناصر نو نوعية.

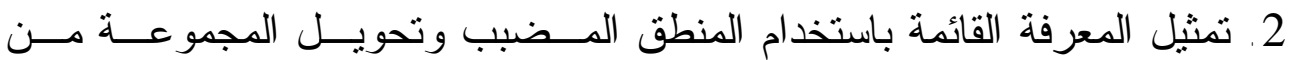

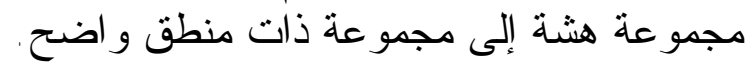

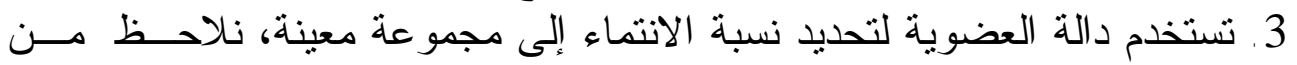

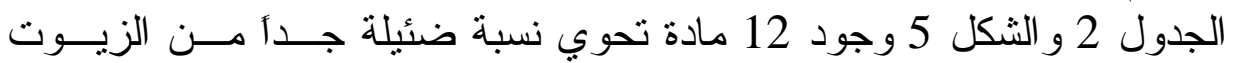

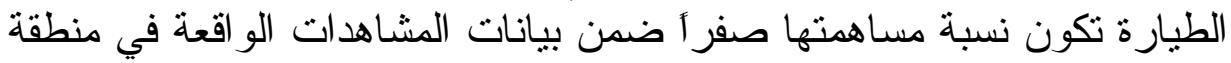

التصنبـب.

إن المنطق المضبب مجال شيق في البحث، فهو لا يتطلب رياضيات شـــاملة

\section{المقترحات}

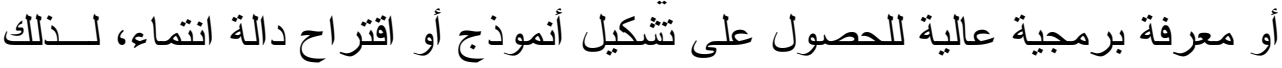
نقتر ح تطوير العمل باتجاهات مختلفة وفي العديد من التطبيقات في الحياة الو اقعية.

\section{أولاً - المر اجع باللغة العربية}

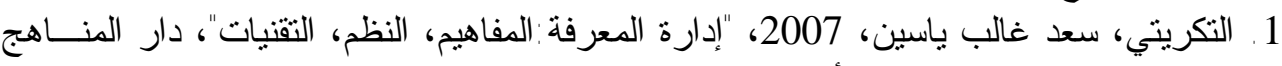
اللنشر و التوزيع، ط1، عمان -الأردن.

2. التكريتي، سعد غالب ياسين، 2000، "تحليل وتصميم نظم المعلومات"، دار المنـــاهج للنـشر و التوزيع، ط1، عمان -الأردن .

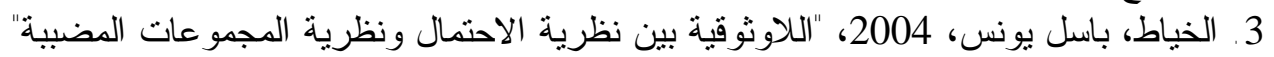

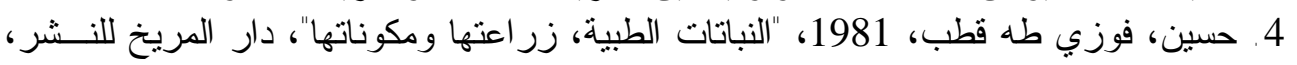
الرياض -المملكة العربية السعودية.

\section{ثانياً - المر اجع باللغة الأجنبية}

1. Zadeh, M. Lotfi, 2004, "Fuzzy logic systems: Origin, Concepts and Trends", NYcomed chair for applied computer science, University of California, Berkeley.

2. Jantzen, Jan, 2004, "Tutorial on fuzzy logic", Tech. report No. 98-E868 (logic), University of Denmark, Denmark.

3. K.A.Hawick, 2004, "Artificial Intellegent", Institute of Information and Mathematical Sciences, $2^{\text {nd }}$ edition, Newzland

4. Britannica concise Encyclopedia: probability theory: Definitions and much more from Answers, 2005,Hogton Press Co. $4^{\text {th }}$ edition, U.K.

- Web site: www.answers.com 